\author{
Military Technical College \\ Kobry El-Kobbah, \\ Cairo, Egypt
}

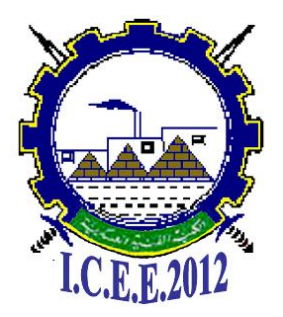

$6^{\text {th }}$ International Conference

on

Chemical \& Environmental

Engineering

29 -31 May, 2012.

ENMA-2

\title{
EFFECT OF POWDER TYPE AND GEOMETRY ON THE INTERNAL BALLISTICS PARAMETERS OF GUNS
}

Dr. Eng. Mohammed H. M. Abuuznein ${ }^{*}$ and Eng. Haytham M. A. Elmokhtar**

\begin{abstract}
This work was carried out to study the possibility of using double base propellants in guns working with single base propellants and vice versa. This was done through studying the effect of changing powder type on the internal ballistics parameters (gases pressure, projectile velocity and gases temperature) through the gun barrel with changing the grain configuration. Two types of guns were studied $(155 \mathrm{~mm}$ howitzer and $100 \mathrm{~mm}$ field guns) with two types of powder (single base -M1-MIL-P-309- and double base -M8-JAN-P-381propellants). Three grain configurations (cord, stripe and single perforated grains) were used for different cases. Computer program (MATLAB) was used to obtain the required results after checking the reliability of the program. The results emphasize the effect of changing powder type on the ballistics parameters through the gun barrel. It was found that it is possible to obtain the required muzzle velocity without exceeding the maximum gases pressure by adjusting the dimensions of powder grains and weight of propellants putting in mind the length of barrel.
\end{abstract}

\section{Keywords:}

Internal Ballistics, Gun, Configuration, Muzzle velocity, Propellant Grai

\footnotetext{
* Associate Professor, Head of Department of Chemical Engineering, Karary University Sudan

** Department of Chemical Engineering Karary University - Sudan
} 


\section{Nomenclature}

\begin{tabular}{|l|l|l|}
\hline DB & Double Base Propellants & \\
\hline GUI & Graphical User Interface & \\
\hline L $(\mathrm{m})$ & Distance & \\
\hline M1 & M1-MIL-P-309- Propellants & \\
\hline M8 & M8-JAN-P-381- Propellants & \\
\hline P (Mpa) & Pressure & \\
\hline S B & Single Base Propellants & \\
\hline T (K) & Temperature & \\
\hline V (m/s) & Velocity & \\
\hline Subscripts & \multicolumn{2}{|l|}{} \\
\hline $\mathrm{k}$ & End of Burning Point & \\
\hline $\mathrm{m}$ & Maximum Pressure Point & \\
\hline $\mathrm{u}$ & Muzzle Point & \\
\hline
\end{tabular}

\section{Introduction}

\subsection{The Ballistics Cycle:}

A gun, regardless of its size, is a device for converting the chemical energy of the propellant into kinetic energy possessed by the projectile. The gun itself, although it is essentially only a tube closed at one end, is a costly and in some ways complicated and delicate piece of engineering. The propellant must be carefully matched to its requirements, to its limitaions of mechanical strength and to its resistance to corrosion and erosion, so as not to degrade its performance or shorten its useful life [1]. When the gun is actuated the charge is ignited by means of a primer, a device designed to produce an explosive burst of flame. This ignites the propellant effectively within a few milliseconds and the flame rapidly burns over the entire surface of the charge. Hot gases are generated from the burning surface of each grain, and the pressure in the chamber, already raised by the explosion of the primer, continues to rise rapidly. Most projectiles offer considerable resistance to propulsion, because some part of their periphery has to be engraved by the rifling of the bore to impart rotation. For fixed rounds, considerable extra force is necessary to effect projectile pull, i.e., to separte the projectile from its case. Because of this resistance the chamer pressure becomes quite high, say 20-80 MPa before shot start occurs. The burning rate of the propellant is dependent on chamber pressure, so although the available volume increases as the projectile moves along the bore, the rate of gas production is so rapid that the pressure continues to increase until the projectile has moved some distance, say $10 \%$ of the bore length. The peak pressure reached is in the region of $450 \mathrm{MPa}$. The pressure then drops, and by the time the projectile has reached the half - way point of the bore the propellant has been entirely consumed. The pressure continues to fall, but the fall is less rapid because the acceleration of the projectile is now less pronounced. At the instant when the projectile leaves the muzzle the pressure has dropped to about $20 \%$ of its peak value, and the acceleration has fallen to zero or little above, due to the continuing friction which has to be overcome [2].

\subsection{Propellant Geometry:}

The geometry of the propellant grain is one of the parameters available to the interior ballisticion to tailor the pressure curve in the gun. Production of gas from agrain depends on the evaluation of the total surface of the grain as the buring proceeds. If the total surface 
remains constant over time the grain is neutral, and if the surface decrease with time the grain is considered regressive.

The perforations in the grain affect the surface area and therefore the burning characteristics. In cylindrical grains, the numbers of perforations are usually one of the numbers in the sequence 1, 7, 19 and 37 [3].

\subsection{Burning of Propellant Grains:}

The burning time of a propellant grain can be controlled by several means, namely $[4,5]$.

1. the size and shape of the propellant grains.

2. the number of perforations in each grain.

3. the web thickness, i.e., the amount of solid propellant between burning surfaces.

4. the quickness, i.e., rate of burning of the grain.

5. the percentage of volatile materials, inert materials, and moisture present [6].

\section{MATHEMATICAL RELATIONS AND SIMULATION}

\subsection{Mathematical Relations:}

The form function is one of the major factors that control the rate of evaluation of gas from the solid propellant. Theoretically, the form function completely determined by the geometry and dimensions of he propellant grains [7].

Different relations were used for modeling and simulation in this work. Herein these relations [8]:

$$
\begin{aligned}
& Z_{m}=\frac{-1}{b\left(2-K_{m}\right)} \\
& 1 \\
& V_{m}=V_{k} Z_{m} \\
& \mathrm{~L}_{\mathrm{m}}=\mathrm{L}^{\prime}\left(\left(1+\mathrm{b} \mathrm{Z}_{\mathrm{m}} / 1+\mathrm{b} \mathrm{Z}_{\mathrm{o}}\right)^{\mathrm{K}_{\mathrm{m}}}-1\right) \\
& \psi_{\mathrm{m}}=\aleph Z_{\mathrm{m}}+\aleph \lambda \mathrm{Z}_{\mathrm{m}}{ }^{2}+\aleph \mu \mathrm{Z}_{\mathrm{m}}{ }^{3} \\
& \frac{T_{m}}{T_{v}}=1-\frac{1}{\psi_{m}} \frac{V^{2}{ }_{m}}{V_{\text {limit }}^{2}} \\
& \mathrm{~L}_{\mathrm{k}}=\mathrm{L}^{\prime}\left[\left(\frac{1+\mathrm{b}}{1+\mathrm{bz}_{\mathrm{o}}}\right)^{\mathrm{K}_{\mathrm{m}}}-1\right] \\
& P_{k}=A(1+b)^{1-K_{m}} \\
& \frac{\mathrm{T}_{\mathrm{k}}}{\mathrm{T}_{\mathrm{v}}}=1-\frac{1}{\psi} \frac{\mathrm{v}_{\mathrm{k}}^{2}}{\mathrm{v}_{\text {lim it }}^{2}}
\end{aligned}
$$




$$
\begin{aligned}
& \mathbf{P}_{\mathrm{u}}=\mathbf{P}_{\mathrm{k}}\left[\frac{\mathbf{L}_{1}+\mathbf{L}_{\mathrm{k}}}{\mathbf{L}_{1}+\mathbf{L}_{\mathrm{u}}}\right]^{\Theta+1} \\
& \mathrm{v}_{\mathrm{u}}=\mathrm{v}_{\text {limit }} \sqrt{1-\left[1-\left(\frac{\mathrm{v}_{\mathrm{k}}}{\mathrm{v}_{\text {limit }}}\right)^{2}\right]\left(\frac{\mathrm{L}_{1}+\mathrm{L}_{\mathrm{k}}}{\mathrm{L}_{1}+\mathrm{L}_{\mathrm{u}}}\right)^{\theta}} \\
& \mathbf{T}_{\mathbf{u}}=\mathbf{T}_{\mathbf{k}}\left[\frac{\mathbf{L}_{1}+\mathbf{L}_{\mathbf{k}}}{\mathbf{L}_{\mathbf{1}}+\mathbf{L}_{\mathbf{u}}}\right]^{\Theta}
\end{aligned}
$$

Where $\mathrm{Z}_{\mathrm{m}}$ : The depth of burning height of grain at the maximum point of pressure (-).

$\mathrm{V}_{\mathrm{m}}$ : The projectile velocity at the maximum point of pressure $(\mathrm{m} / \mathrm{s})$.

$\mathrm{L}_{\mathrm{m}}$ : The length of barrel at the maximum point of pressure $(\mathrm{m})$.

$\mathrm{P}_{\mathrm{m}}$ : The maximum pressure (MPa).

$\psi_{\mathrm{m}}$ : The ratio of burned propellant at the maximum point of pressure (-).

$\mathrm{T}_{\mathrm{m}}$ : The temperature at the maximum point of pressure $(\mathrm{K})$.

$\mathrm{T}_{\mathrm{v}}$ : The explosion temperature (K).

$\mathrm{L}_{\mathrm{k}}$ : The distance at the end of burning $(\mathrm{m})$.

$\mathrm{P}_{\mathrm{K}}$ : The pressure at the end of burning $(\mathrm{MPa})$.

$V_{K}$ : The velocity of projectile at end of burning $(\mathrm{m} / \mathrm{s})$.

$\mathrm{T}_{\mathrm{k}}$ : The temperature at the end of burning $(\mathrm{K})$.

$\mathrm{P}_{\mathrm{u}}$ : The pressure at the muzzle (MPa).

$\mathrm{T}_{\mathrm{u}}$ : The temperature at the muzzle $(\mathrm{K})$.

$\mathrm{V}_{\mathrm{u}}$ : The muzzle velocity $(\mathrm{m} / \mathrm{s})$.

( $\mathrm{a}, \mathrm{b}, \mathrm{J}, \mathrm{K}_{\mathrm{m}}, A$ and $\lambda$ ): The characteristic parameters (constant).

$(\aleph, \aleph \lambda, \aleph \mu):$ coefficients of geometrical shape of powder grain (-).

\subsection{Simulation:}

Simulation used to study effect of changing powder type and geometry configuration on internal ballistics parameters of different types of gun caliber using different types of propellant with different grain configurations by using computer program (MATLAB).

Computer program (MATLAB) was employed to construct the M.File program of solution and graphical user interface (GUI) program. After introducing the inputs data, the program was used to calculate the internal ballistic parameters of different types of gun caliber by using different types of propellants and different types of grain configurations. The output results were tabulated and plotted automatically by the program. The reliability of this program was examined by comparing its calculated results with the parameters given for anther gun $(175 \mathrm{~mm})$. 


\section{RESULTS AND DISCUSSION}

\subsection{Results of the $155 \mathrm{~mm}$ Howitzer:}

Tables (1) to (6) and figures from (1) to (6) illustrate the effect of varying powder type with different grain configurations on the internal ballistics parameters along the barrel of $155 \mathrm{~mm}$ howitzer. This howitzer was originally works with single base propellants. Replacing the single base by double base propellants for all grain configurations shows the following:

The muzzle velocity becomes very high compared with that when using single base propellants; this is due to the high energy of double base propellants. These results are as expect but it is needed to insure that maximum pressure will not exceed the permissible maximum pressure

The double base propellants gave higher pressure compared with single base propellants. This is due to the resume of the nitroglycerine. Notice that the pressure can be adjusted by decreasing the amount of propellants weight.

The temperature produced by the double base propellants is higher than that produced by the single base propellants. This was obvious, due to the high-energy contents of double base propellants.

The end of burning of the double base propellants occurred at early point in the barrel compared with that of the single base propellants. This is due to the difference on the burning rates.

\subsection{Results of the $100 \mathrm{~mm}$ Field Gun:}

Tables (7), (12) and figures (7), (12) show the effect of replacing powder type using different grain configurations on the internal ballistics parameters along the barrel of $100 \mathrm{~mm}$ field gun. This field gun is originally works with double base propellants. Replacing the double base by single base propellants for all grain configurations showed the following results:

The muzzle velocity was very low compared to the double base propellants. This was due to the relative low energy of the single base propellants. The result was not expected.

The single base propellants give lower gases pressure compared to the double base propellants.

The temperature producing by the single base propellants is lower than that produced by the double base propellants. This due to the relative low energy contents of single base propellants.

\subsection{Effects of Grain Configuration:}

The effects of grain configuration (geometry) were shown in different tables and figures. It is clear that same configuration give same behavior even when the parameter values are different. This can be useful for optimizing internal ballistic parameters specially the muzzle velocity and the maximum pressure. The cord configuration gives the maximum pressure, muzzle temperature and minimum muzzle velocity while single perforated configuration shows opposite behavior. Strip configuration gives in between parameter behavior

\section{CONCLUSION}

From this paper the following points can be concluded:

1. The maximum gases pressure is relatively high when using double base propellants for all grain configurations. 
2. The double base propellants (M8) gives higher gases temperature through barrel compared with the single base propellants (M1).

3. The Single base propellants (M1) gives lower gases pressure compared with double base propellants (M8).

4. The comparison between single base propellants (M1) and double base propellants (M8) showed that the double base propellants gives higher muzzle velocity. At the same time gives higher gases temperature and pressure inside the gun barrel.

5. The behavior of internal ballistics parameters on the three types of gun with different grain configurations and two types of propellants shows an excellent agreement with the literature in this area.

6. A reliable and user-friendly computer program (MATLAB) was designed to achieve the results of this research. This program can be used for other types of gun with different types of propellants and different grain configurations.

\section{References}

[1] http://home.snafu.de/l.moeller/Ballistics/Airdrag.html, Mar 2010.

[2] http://www.molonlabe.net/johns/extbal.html, June 2010.

[3] Krier H. and Summerfield M., "Intrior Ballistics of guns", American Institute of Aeronautics and Astronautics, New York, 1979

[4] Davis G.and Tenny L., "The Chemistry of Powder and Explosives", Moore \& Matthes Ltd, London, 1943.

[5] Chaiken R. F., “Combustion and Flame 3”, 285, Pergamon Press, USA 1959.

[6] Headquarters., "Military Explosive", Department of the army, Washington, September 1990.

[7] O'Shaughnessy P. "Students major in running guns: Buy arms in Dixie cheap to sell on city streets", New York Daily News, Sep 2002.

[8] Hague T. T, "Study of Changing Grain Configurations on Internal Ballistics parameters", MSc, Khartoum, 2004.

Table (1): Internal ballistics parameters of $155 \mathrm{~mm}$ howitzer using cord grains of (M8) propellants.

\begin{tabular}{|l|c|c|c|c|}
\hline \multirow{2}{*}{ Parameter } & \multicolumn{4}{|c|}{ Positions in the Gun Barrel } \\
\cline { 2 - 5 } & Initial & Max Pressure & End of Burring & Muzzle \\
\hline $\mathrm{L}(\mathrm{m})$ & 0.0 & 0.3295 & 2.3865 & 6.0450 \\
\hline $\mathrm{P}(\mathrm{MPa})$ & 44 & 527.77 & 111.09 & 43.926 \\
\hline $\mathrm{V}(\mathrm{m} / \mathrm{s})$ & 0.0 & 311.19 & 710.71 & 961.88 \\
\hline $\mathrm{T}(\mathrm{K})$ & 3695 & 3457.3 & 3152.0 & 2700.4 \\
\hline
\end{tabular}


Table (2): Internal ballistics parameters of $155 \mathrm{~mm}$ howitzer using Strip grains of (M8) propellants.

\begin{tabular}{|l|l|l|l|l|}
\hline Parameter & Initial & Max Pressure & End of Burring & Muzzle \\
\hline L $(\mathrm{m})$ & 0.0 & 0.9981 & 2.6871 & 6.0450 \\
\hline $\mathrm{P}(\mathrm{MPa})$ & 44 & 279.99 & 227.47 & 100.38 \\
\hline $\mathrm{V}(\mathrm{m} / \mathrm{s})$ & 0.0 & 406.72 & 692.97 & 925.78 \\
\hline $\mathrm{T}(\mathrm{K})$ & 3695 & 3392.0 & 3178.8 & 2773.7 \\
\hline
\end{tabular}

Table (3): Internal ballistic parameters of $155 \mathrm{~mm}$ howitzer using single perforated grains of (M8) propellants.

\begin{tabular}{|l|l|l|l|l|}
\hline Parameter & Initial & Max Pressure & End of Burring & Muzzle \\
\hline L $(\mathrm{m})$ & 0.0 & 0.7041 & 2.1585 & 6.0450 \\
\hline $\mathrm{P}(\mathrm{MPa})$ & 44 & 371.00 & 266.18 & 96.136 \\
\hline $\mathrm{V}(\mathrm{m} / \mathrm{s})$ & 0.0 & 388.05 & 701.16 & 975.43 \\
\hline $\mathrm{T}(\mathrm{K})$ & 3695 & 3402.5 & 3166.5 & 2672.2 \\
\hline
\end{tabular}

Table (4): Internal ballistics parameters of $155 \mathrm{~mm}$ howitzer using cord grains of (M1) propellants.

\begin{tabular}{|l|l|l|l|l|}
\hline Parameter & Initial & Max Pressure & End of Burring & Muzzle \\
\hline L $(\mathrm{m})$ & 0.0 & 0.3562 & 3.5098 & 6.0450 \\
\hline $\mathrm{P}(\mathrm{MPa})$ & 44 & 418.40 & 62.197 & 35.257 \\
\hline $\mathrm{V}(\mathrm{m} / \mathrm{s})$ & 0.0 & 289.93 & 707.76 & 841.37 \\
\hline $\mathrm{T}(\mathrm{K})$ & 2417 & 2239.5 & 1983.6 & 1804.6 \\
\hline
\end{tabular}

Table (5): Internal ballistics parameters of $155 \mathrm{~mm}$ howitzer using strip grains of (M1) propellants.

\begin{tabular}{|l|l|l|l|l|}
\hline \multirow{2}{*}{ Parameter } & \multicolumn{4}{l}{ Positions in the Gun Barrel } \\
\cline { 2 - 5 } & Initial & Max Pressure & End of Burring & Muzzle \\
\hline $\mathrm{L}(\mathrm{m})$ & 0.0 & 0.9227 & 3.7643 & 6.0450 \\
\hline $\mathrm{P}(\mathrm{MPa})$ & 44 & 205.65 & 138.60 & 84.324 \\
\hline $\mathrm{V}(\mathrm{m} / \mathrm{s})$ & 0.0 & 339.10 & 686.44 & 809.81 \\
\hline $\mathrm{T}(\mathrm{K})$ & 2417 & 2215.6 & 2009.3 & 1849.6 \\
\hline
\end{tabular}


Table (6): Internal ballistics parameters of $155 \mathrm{~mm}$ howitzer using single perforated grains of (M1) propellants.

\begin{tabular}{|l|l|l|l|l|}
\hline Parameter & Initial & Max Pressure & End of Burring & Muzzle \\
\hline $\mathrm{L}(\mathrm{m})$ & 0.0 & 0.6992 & 2.9926 & 6.0450 \\
\hline $\mathrm{P}(\mathrm{MPa})$ & 44 & 279.37 & 165.68 & 80.186 \\
\hline $\mathrm{V}(\mathrm{m} / \mathrm{s})$ & 0.0 & 338.64 & 696.26 & 864.77 \\
\hline $\mathrm{T}(\mathrm{K})$ & 2417 & 2213.0 & 1997.6 & 1770.0 \\
\hline
\end{tabular}

Table (7): Internal ballistics parameters of $100 \mathrm{~mm}$ field gun using cord grains of (M8) propellants.

\begin{tabular}{|l|l|l|l|l|}
\hline Parameter & Initial & Max Pressure & End of Burring & Muzzle \\
\hline $\mathrm{L}(\mathrm{m})$ & 0.0 & 0.2595 & 1.1117 & 4.7570 \\
\hline $\mathrm{P}(\mathrm{MPa})$ & 44 & 1039.2 & 461.49 & 107.74 \\
\hline $\mathrm{V}(\mathrm{m} / \mathrm{s})$ & 0.0 & 419.70 & 849.38 & 1328.9 \\
\hline $\mathrm{T}(\mathrm{K})$ & 3695 & 3458.6 & 3216.6 & 2524.1 \\
\hline
\end{tabular}

Table (8): Internal ballistics parameters of 100mm field gun using strip grains of (M8) propellants.

\begin{tabular}{|l|l|l|l|l|}
\hline Parameter & Initial & Max Pressure & End of Burring & Muzzle \\
\hline $\mathrm{L}(\mathrm{m})$ & 0.0 & 0.4968 & 1.3305 & 4.7570 \\
\hline $\mathrm{P}(\mathrm{MPa})$ & 44 & 727.61 & 556.95 & 152.44 \\
\hline $\mathrm{V}(\mathrm{m} / \mathrm{s})$ & 0.0 & 492.63 & 843.18 & 1286.6 \\
\hline $\mathrm{T}(\mathrm{K})$ & 3695 & 3419.6 & 3223.6 & 2597.5 \\
\hline
\end{tabular}

Table (9): Internal ballistics parameters of $100 \mathrm{~mm}$ field gun using single perforated grains of (M8) propellants.

\begin{tabular}{|l|l|l|l|l|}
\hline \multirow{2}{*}{ Parameter } & \multicolumn{4}{l}{ Positions in the Gun Barrel } \\
\cline { 2 - 5 } & Initial & Max Pressure & End of Burring & Muzzle \\
\hline $\mathrm{L}(\mathrm{m})$ & 0.0 & 0.6036 & 1.4328 & 4.7570 \\
\hline $\mathrm{P}(\mathrm{MPa})$ & 44 & 659.86 & 548.29 & 160.58 \\
\hline $\mathrm{V}(\mathrm{m} / \mathrm{s})$ & 0.0 & 519.67 & 840.89 & 1267.9 \\
\hline $\mathrm{T}(\mathrm{K})$ & 3695 & 3405.3 & 3226.1 & 2629.1 \\
\hline
\end{tabular}


Table (10): Internal ballistics parameters of $100 \mathrm{~mm}$ field gun using cord grains of (M1) propellants.

\begin{tabular}{|l|l|l|l|l|}
\hline Parameter & Initial & Max Pressure & End of Burring & Muzzle \\
\hline $\mathrm{L}(\mathrm{m})$ & 0.0 & 0.2683 & 1.4600 & 4.7570 \\
\hline $\mathrm{P}(\mathrm{MPa})$ & 44 & 855.39 & 306.42 & 87.858 \\
\hline $\mathrm{V}(\mathrm{m} / \mathrm{s})$ & 0.0 & 388.91 & 847.34 & 1197.6 \\
\hline $\mathrm{T}(\mathrm{K})$ & 2417 & 2241.1 & 2033.9 & 1651.6 \\
\hline
\end{tabular}

Table (11): Internal ballistics parameters of $100 \mathrm{~mm}$ field gun using strip grains of (M1) propellants.

\begin{tabular}{|l|l|l|l|l|}
\hline Parameter & Initial & Max Pressure & End of Burring & Muzzle \\
\hline $\mathrm{L}(\mathrm{m})$ & 0.0 & 0.4799 & 1.7573 & 4.7570 \\
\hline $\mathrm{P}(\mathrm{MPa})$ & 44 & 569.76 & 368.23 & 126.84 \\
\hline $\mathrm{V}(\mathrm{m} / \mathrm{s})$ & 0.0 & 430.85 & 839.95 & 1152.3 \\
\hline $\mathrm{T}(\mathrm{K})$ & 2417 & 2223.9 & 2040.5 & 1708.4 \\
\hline
\end{tabular}

Table (12): Internal ballistics parameters of $100 \mathrm{~mm}$ field gun using single perforated grains of (M1) propellants.

\begin{tabular}{|l|l|l|l|l|}
\hline Parameter & Initial & Max Pressure & End of Burring & Muzzle \\
\hline $\mathrm{L}(\mathrm{m})$ & 0.0 & 0.5662 & 1.9016 & 4.7570 \\
\hline $\mathrm{P}(\mathrm{MPa})$ & 44 & 507.60 & 359.75 & 134.22 \\
\hline $\mathrm{V}(\mathrm{m} / \mathrm{s})$ & 0.0 & 443.99 & 837.23 & 1131.8 \\
\hline $\mathrm{T}(\mathrm{K})$ & 2417 & 2218.6 & 2042.9 & 1733.4 \\
\hline
\end{tabular}




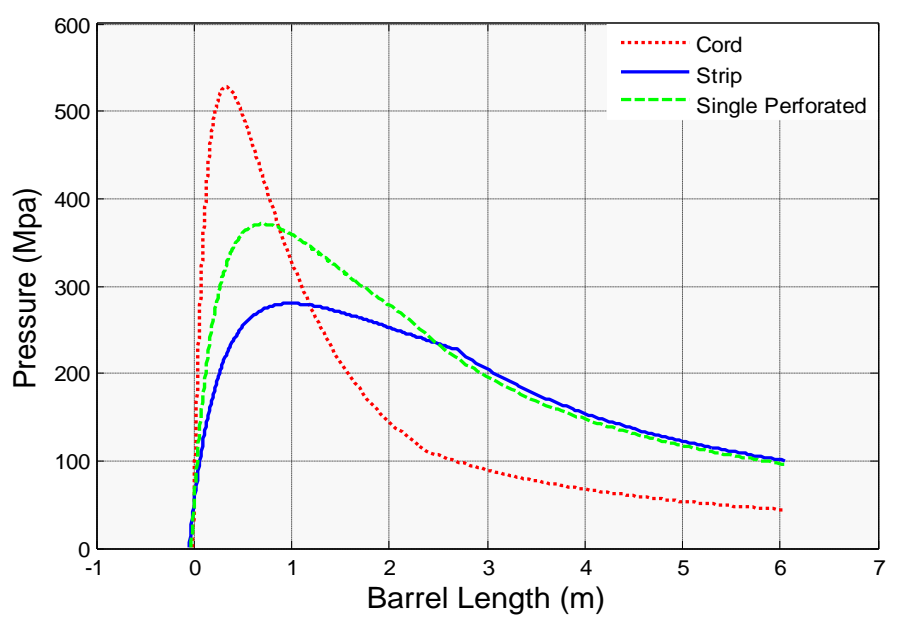

Fig (3): Change of pressure through the gun barrel for $155 \mathrm{~mm}$ Howitzer with different grain configurations using (M8) propellants.

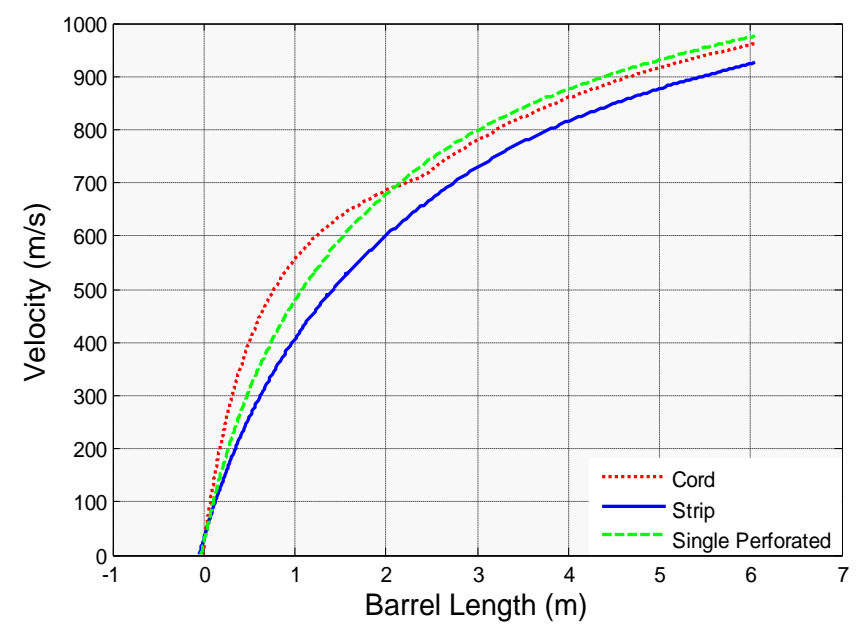

Fig (4): Change of velocity through the gun barrel for $155 \mathrm{~mm}$ Howitzer with different grain configurations using (M8) propellants.

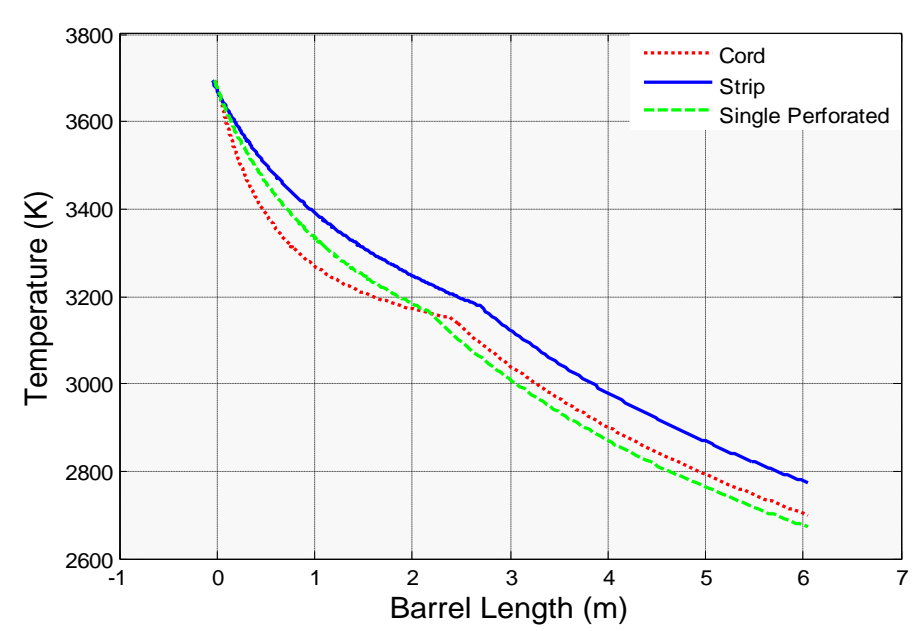

Fig (5): Change of temperature through the gun barrel for $155 \mathrm{~mm}$ howitzer with different grain configurations using (M8) propellants. 


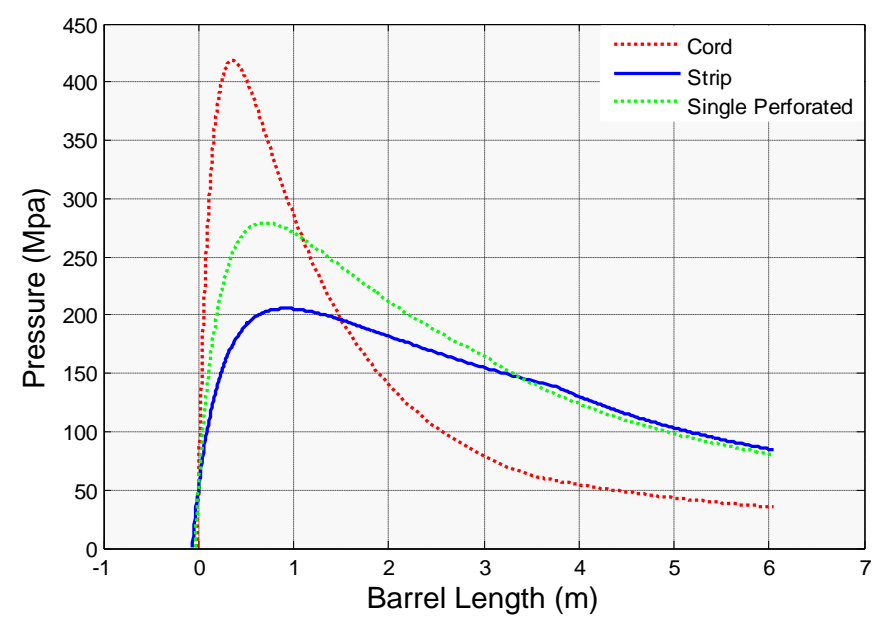

Fig (6): Change of pressure through the gun barrel for $155 \mathrm{~mm}$ howitzer with different grain configurations using (M1) propellants.

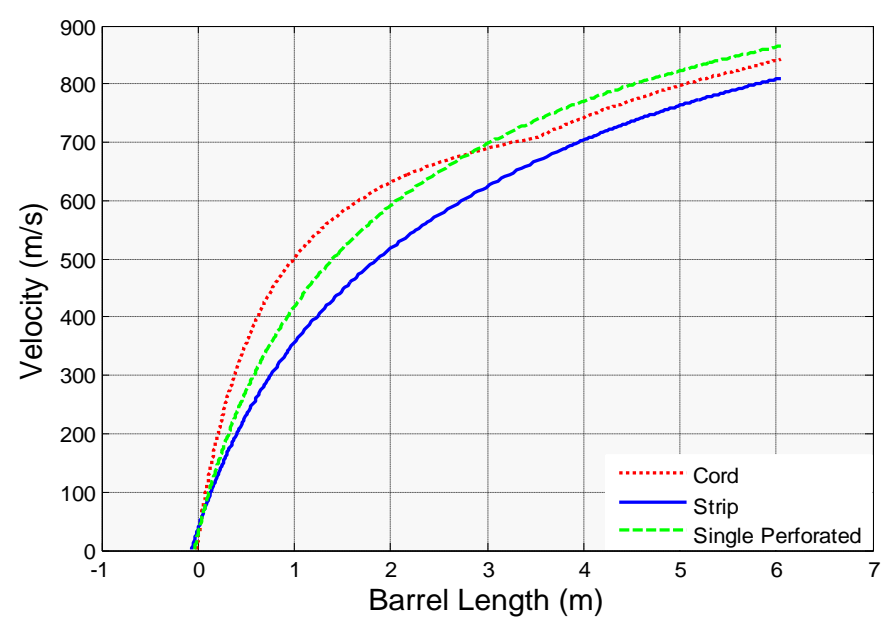

Fig (7): Change of velocity through the gun barrel for $155 \mathrm{~mm}$ howitzer with different grain configurations using (M1) propellants.

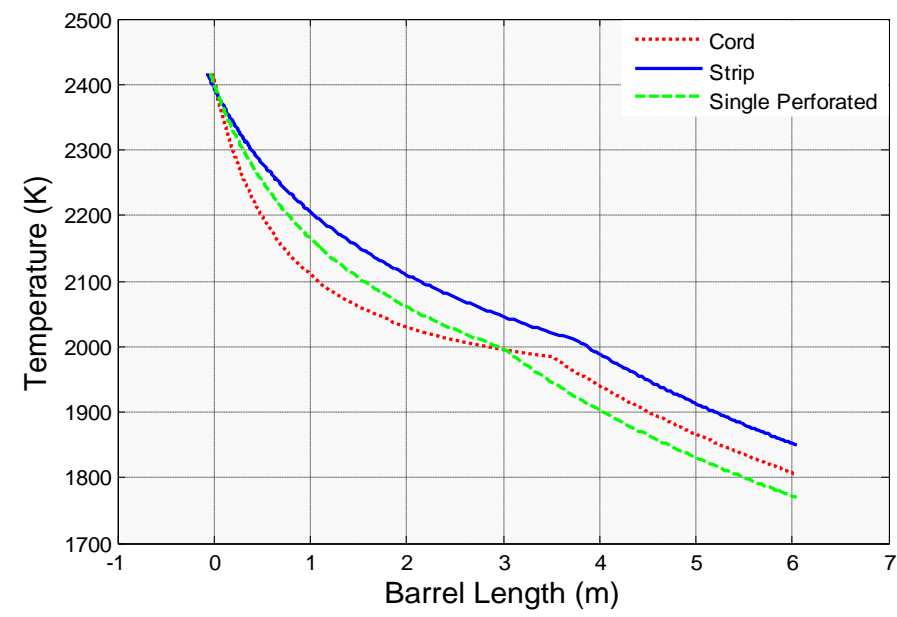

Fig (8): Change of temperature through the gun barrel for $155 \mathrm{~mm}$ howitzer with different grain configurations using (M1) propellants. 


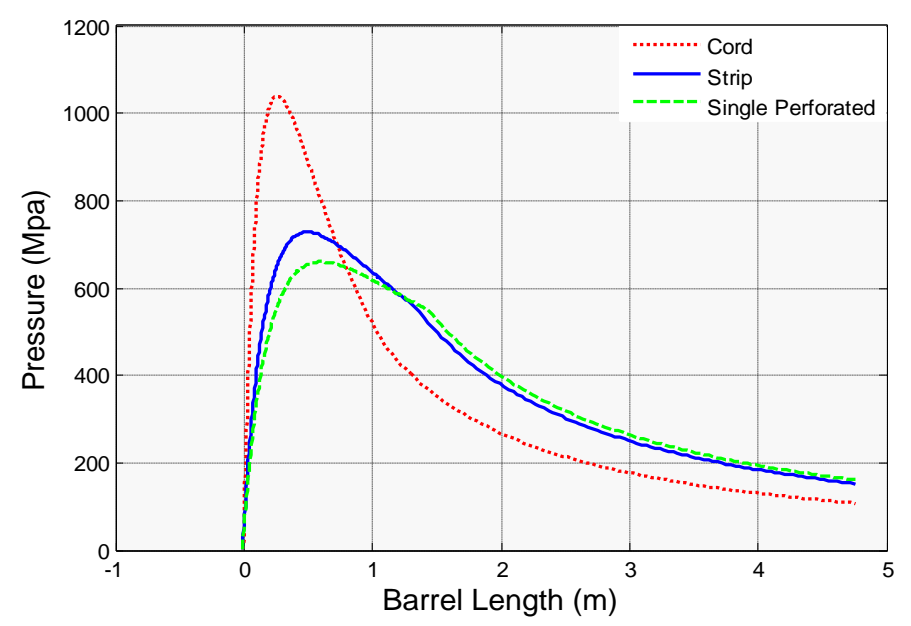

Fig (9): Change of pressure through the gun barrel for $100 \mathrm{~mm}$ field gun with different grain configurations using (M8) propellants.

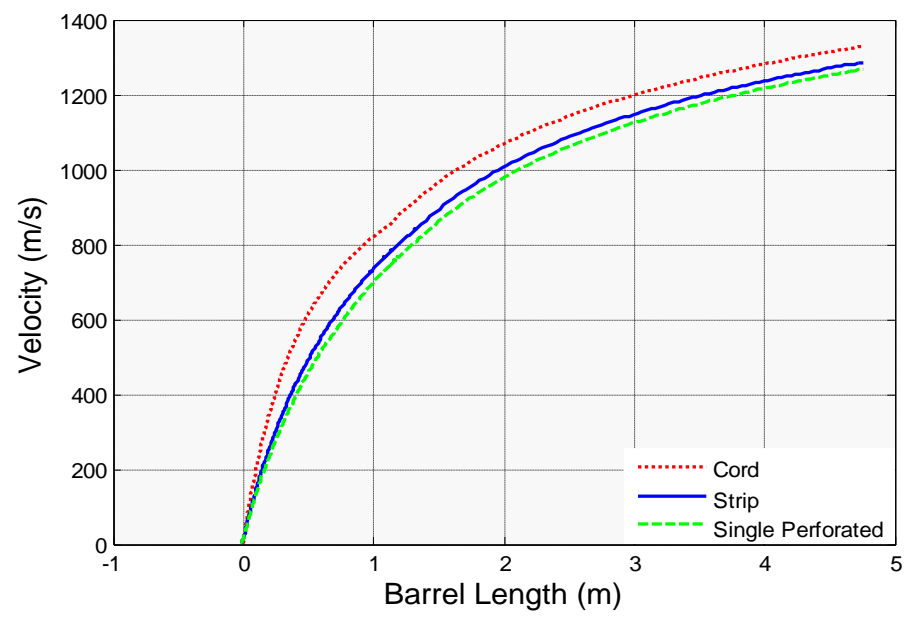

Fig (10): Change of velocity through the gun barrel for $100 \mathrm{~mm}$ field gun with different grain configurations using (M8) propellants.

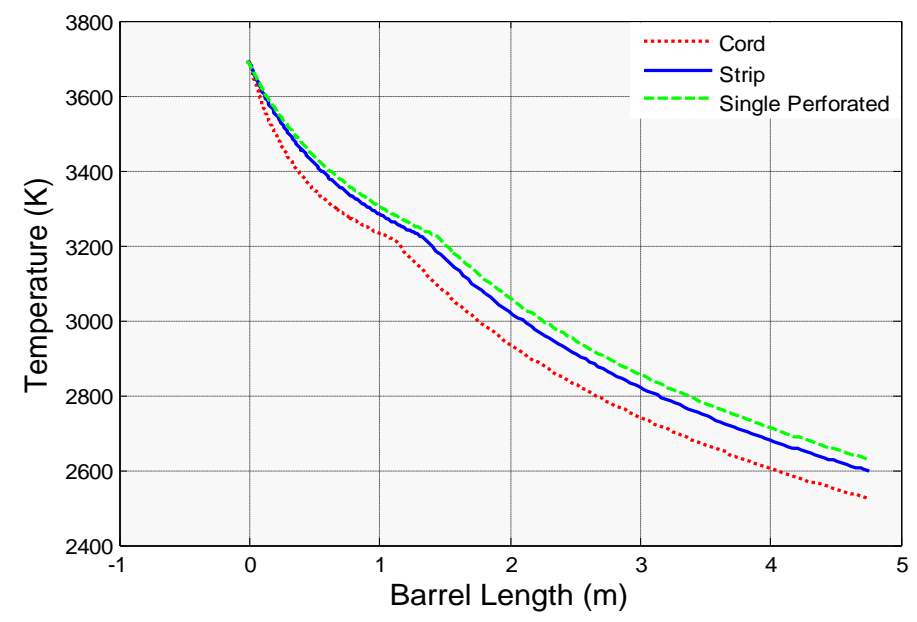

Fig (11): Change of temperature through the gun barrel for $100 \mathrm{~mm}$ field gun with different grain configurations using (M8) propellants. 


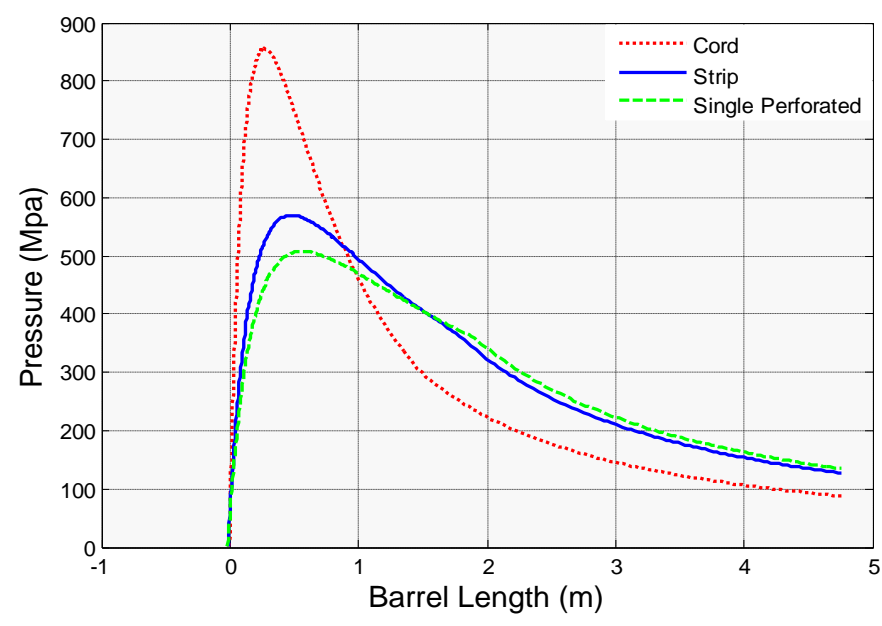

Fig (12): Change of pressure through the gun barrel for 100mm field gun with different grain configurations using (M1) propellants.

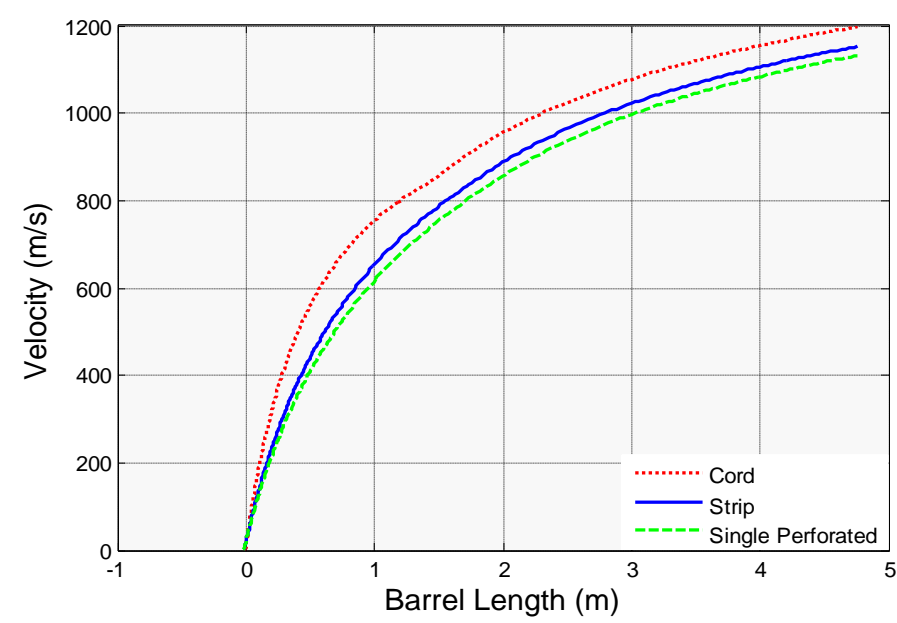

Fig (13): Change of velocity through the gun barrel for $100 \mathrm{~mm}$ field gun with different grain configurations using (M1) propellants.

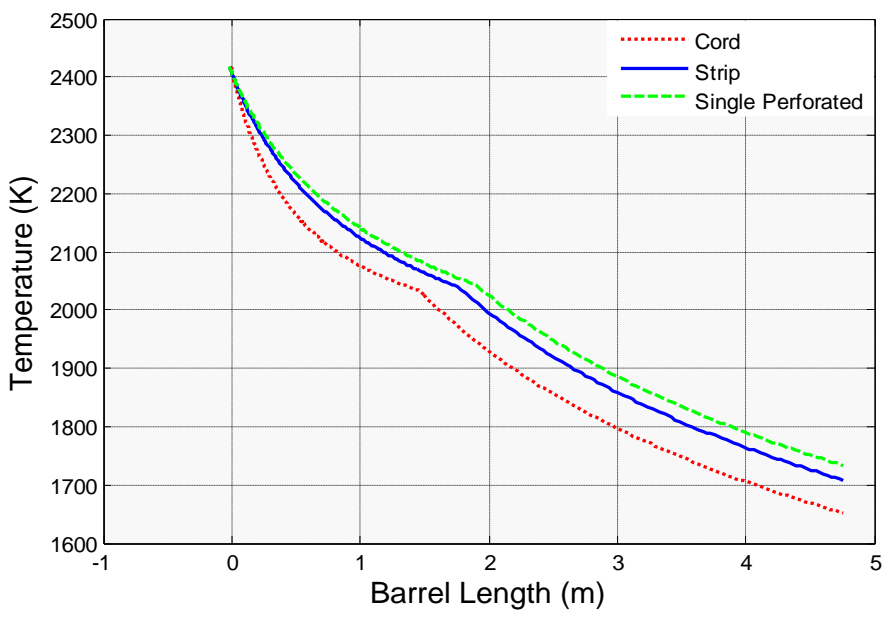

Fig (14): Change of temperature through the gun barrel for $100 \mathrm{~mm}$ field gun with different grain configurations using (M1) propellants. 